\title{
Haustorium Formation in Medicago truncatula Roots Infected by Phytophthora palmivora Does Not Involve the Common Endosymbiotic Program Shared by Arbuscular Mycorrhizal Fungi and Rhizobia
}

\author{
Rik Huisman, ${ }^{1}$ Klaas Bouwmeester, ${ }^{2,3}$ Marijke Brattinga, ${ }^{1}$ Francine Govers, ${ }^{2}$ Ton Bisseling, ${ }^{1}$ and \\ Erik Limpens ${ }^{1}$ \\ ${ }^{1}$ Department of Plant Sciences, Laboratory of Molecular Biology, Wageningen University, Droevendaalsesteeg 1, 6708 PB, \\ Wageningen, The Netherlands; ${ }^{2}$ Department of Plant Sciences, Laboratory of Phytopathology, Wageningen University; \\ ${ }^{3}$ Plant-Microbe Interactions, Department of Biology, Faculty of Science, Utrecht University, PO Box 800.56 3508 TB, Utrecht, \\ The Netherlands
}

Submitted 12 June 2015. Accepted 5 August 2015.

\begin{abstract}
In biotrophic plant-microbe interactions, microbes infect living plant cells, in which they are hosted in a novel membrane compartment, the host-microbe interface. To create a host-microbe interface, arbuscular mycorrhizal (AM) fungi and rhizobia make use of the same endosymbiotic program. It is a long-standing hypothesis that pathogens make use of plant proteins that are dedicated to mutualistic symbiosis to infect plants and form haustoria. In this report, we developed a Phytophthora palmivora pathosystem to study haustorium formation in Medicago truncatula roots. We show that $P$. palmivora does not require host genes that are essential for symbiotic infection and host-microbe interface formation to infect Medicago roots and form haustoria. Based on these findings, we conclude that $P$. palmivora does not hijack the ancient intracellular accommodation program used by symbiotic microbes to form a biotrophic host-microbe interface.
\end{abstract}

Plants can be colonized by a diversity of biotrophic microbes that invade living plant cells. The relation of these microbes with their host plant varies from mutualistic symbiosis to pathogenesis. A common event in biotrophic interactions is the formation of a host-microbe interface. A host-microbe interface is a specialized membrane compartment in which all or part of the microbe resides within the plant cell. This interface is the fundament of biotrophy, as it facilitates the controlled exchange of nutrients and signals between plant and microbe. Well-known examples of host-microbe interfaces are the peri-arbuscular membrane surrounding arbuscules formed by arbuscular mycorrhiza (AM) fungi, the peri-bacteroid membrane surrounding bacteria in the symbiosis between legumes and rhizobia, and the extrahaustorial membrane surrounding haustoria formed by pathogenic fungi and oomycetes (Parniske 2000). The intracellular colonization of plant cells, including host-microbe interface formation, requires the active contribution of the plant. Decades of research provided insight into the mechanisms that control the infection and host-microbe interface formation in symbiotic interactions

Corresponding author: E. Limpens: E-mail: erik.limpens@wur.nl

*The $\boldsymbol{e}$-Xtra logo stands for "electronic extra" and indicates that two supplementary figures and two supplementary tables are published online.

๑) 2015 The American Phytopathological Society
(Harrison 2012; Oldroyd 2013). However, how pathogens force plants to cooperate in their intracellular colonization remains an intriguing question.

AM symbiosis is one of the most ancient biotrophic plantmicrobe interactions that emerged around 450 million years ago (Redecker et al. 2000). Endosymbiosis between plants and nitrogen-fixing bacteria and interactions between plants and biotrophic pathogens evolved multiple times independently later in evolution (Baxter et al. 2010; Doyle 2011; Spanu et al. 2010). The genetic constraints for intracellular infection of plant cells are highlighted by the fact that several key components of AM symbiosis have been co-opted in the more recently evolved endosymbiosis between legumes and rhizobia (Table 1). Both AM fungi and rhizobium bacteria produce lipochito-oligosaccharide signal molecules (LCO) that activate a set of common symbiotic signaling (SYM) genes required for intracellular infection (Oldroyd 2013; Parniske 2000). Furthermore, AM fungi and rhizobium bacteria share the same exocytosis pathway, marked by two v-SNAREs ( $N$-ethylmaleimide-sensitive factor adaptor protein receptors) (VAMP721d and VAMP721e) to form arbuscules and symbiosomes, respectively (Ivanov et al. 2012). The signaling pathway shared by AM symbiosis and legumerhizobium symbiosis has been co-opted independently in the interaction between rhizobia and the nonlegume genus Parasponia (Op den Camp et al. 2011). Also, in the interaction of plants with actinorhizal bacteria, in which bacteria are hosted in membrane compartments, common SYM genes are indispensable (Gherbi et al. 2008; Svistoonoff et al. 2014). These data suggest that AM symbiosis provided the blueprint for many endosymbiotic relations that evolved later. This has raised the intriguing hypothesis that many biotrophic microbes, including pathogens, make use of a generic program to be accommodated inside plant cells (Parniske 2000; Rey and Schornack 2013).

This hypothesis is supported by observations that show overlap in pathogenesis and symbiosis. i) Haustoria and arbuscules are structurally similar, as both are devoid of a structured cell wall and contain a specialized plant-derived membrane with a unique protein composition (Gutjahr and Parniske 2013; Hardham 2007; Lu et al. 2012; O'Connell and Panstruga 2006). ii) Cells that host haustoria undergo endoreduplication, similar to cells that host arbuscules and symbiosomes (Bainard et al. 2011; Chandran et al. 2010; Vinardell et al. 2003; Williamson and Hussey 1996). iii) Plant cells often respond to pathogen invasion 
by aggregating the cytoplasm at the site of contact. In the case of infection of Medicago truncatula by Colletotrichum trifolii and Phoma medicaginis, this aggregation was shown to depend on the common SYM pathway (Genre et al. 2009). iv) Although pathogens are not known to produce LCO, they may activate common SYM genes in an alternative manner (Liang et al. 2014). Along with LCO, short chain chitin oligomers were also implicated in symbiotic signaling between AM fungi and Medicago (Genre et al. 2013). In addition, the receptors for perceiving chitin and symbiotic LCO are related (De Mita et al. 2014; Nakagawa et al. 2011), as well as early transcriptional responses toward mycorrhiza and pathogens (Güimil et al. 2005).

In this study, we addressed the question whether a generic endosymbiosis program, which is used by different symbiotic microbes to establish infection and intracellular accommodation, is also used by pathogens to infect Medicago roots and to form haustoria. Therefore, we set up a suitable pathosystem to study infection and haustorium formation in Medicago roots. We selected the oomycete Phytophthora palmivora as a suitable hemibiotrophic pathogen that forms haustoria in Medicago roots and monitored disease development and haustorium formation. We inoculated an extensive collection of Medicago mutants that are impaired in plant (intracellular) colonization during AM and rhizobial symbiosis with $P$. palmivora. In addition, we examined the role of the vesicle SNAREs VAMP721d and VAMP721e, which mark a symbiosis-specific exocytosis pathway required for intracellular accommodation, for their role in haustorium formation.

\section{RESULTS}

\section{Infection of Medicago roots by different Phytophthora species.}

In order to find a pathogen that forms haustoria in Medicago roots, we focused on Phytophthora species, as these are known to invade roots of a broad range of plant species as causal agents of root rot. Furthermore, Phytophthora spp. are able to form haustoria in roots (Rey and Schornack 2013; Wang et al. 2011). In an initial screen, we inoculated 1-week-old Medicago seedlings (Jemalong A17) with mycelial plugs of $P$. capsici, $P$. cinnamomi, $P$. medicaginis, or $P$. palmivora. We analyzed

Table 1. Overview of mutants used in this study, and their symbiotic defects ${ }^{\mathrm{a}}$

\begin{tabular}{|c|c|c|c|c|c|c|}
\hline Gene & Allele & Backgr. & Encoding & $\begin{array}{l}\text { Mutant phenotype } \\
\text { AM symbiosis }\end{array}$ & $\begin{array}{l}\text { Mutant phenotype } \\
\text { rhizobium symbiosis }\end{array}$ & Reference \\
\hline$D M I 2$ & $T R 25$ & A17 & LRR receptor kinase & Col-, Arb- & Nod-, Inf- & Endre et al. 2002 \\
\hline DMI3 & $T R V 25$ & A17 & Calcium calmodulin binding kinase & Col-, Arb- & Nod-, Inf- & Lévy et al. 2004 \\
\hline$V P Y$ & NF6898 & R108 & Major sperm domain ankyrin protein & Arb- & Nod-, Inf \pm , Bar- & $\begin{array}{l}\text { Pumplin et al. } 2010 \\
\text { Murray et al. } 2011\end{array}$ \\
\hline IPD3 & $\mathrm{Te} 7$ & A17 & Transcription factor & Col \pm & Bar- & $\begin{array}{l}\text { Ovchinnikova et al. } 2011 \\
\text { Horváth et al. } 2011\end{array}$ \\
\hline NSP1 & nsp1-1 & A17 & GRAS type transcription factor & Col \pm & Nod-, Inf- & $\begin{array}{l}\text { Smit et al. } 2005 \\
\text { Delaux et al. } 2013 \mathrm{a}\end{array}$ \\
\hline NSP2 & $n s p 2-2$ & A17 & GRAS type transcription factor & Col \pm & Nod-, Inf- & $\begin{array}{l}\text { Kaló et al. 2005; } \\
\text { Maillet et al. } 2011\end{array}$ \\
\hline$N F P$ & C31 & A17 & LysM-type receptor kinase & $\begin{array}{l}\text { Lower sensitivity } \\
\text { to Myc-LCO }\end{array}$ & Nod-, Inf- & Ben Amor et al. 2003 \\
\hline RAM2 & $\operatorname{ram} 2-1$ & A17 & Glycerol-3-phosphate acyl transferase & Col, \pm- Arb \pm & - & Wang et al. 2012 \\
\hline$L Y K 3$ & B56 & A17 & LysM-type receptor kinase & Col \pm & Nod-, Inf- & $\begin{array}{l}\text { Limpens et al. } 2003 \\
\text { Zhang et al. } 2015\end{array}$ \\
\hline
\end{tabular}

a Arbuscular mycorrhizal (AM) symbiosis phenotypes are described as the ability of the fungus to colonize (Col) plant roots and form arbuscules (Arb). Rhizobium symbiosis phenotypes are described as the ability of bacteria to form infection threads (Inf) and nodules (Nod) as well as release of bacteria (Bar) from infection threads to form symbiosomes. Minus (-) represents the total absence of a symbiotic stage, \pm represents reduced intensity of a symbiotic stage.
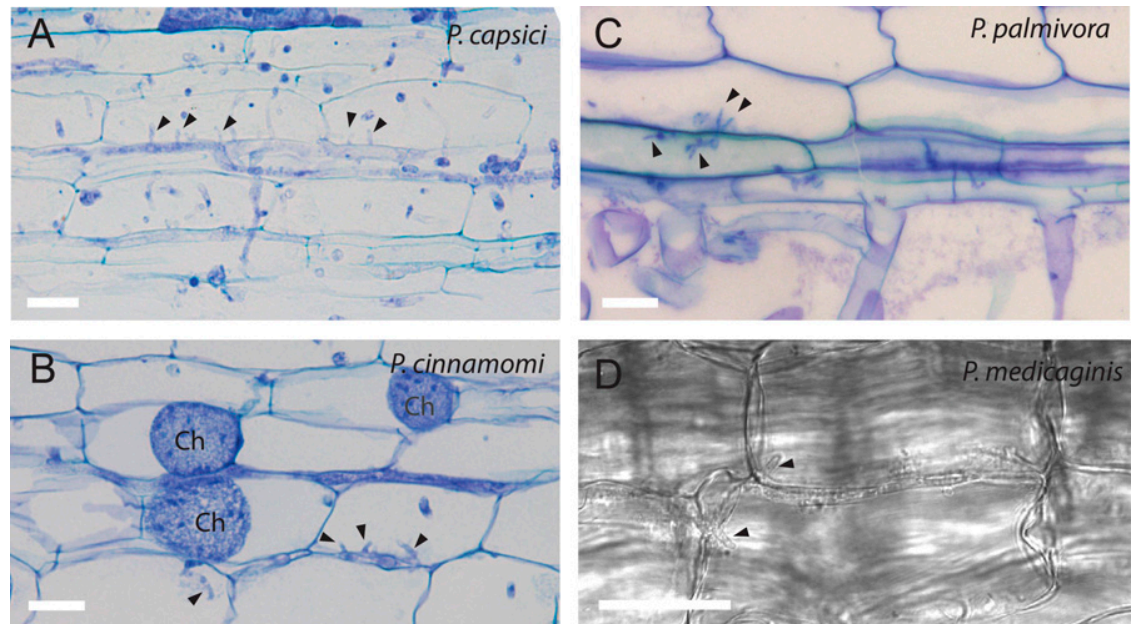

Fig. 1. Infection of Medicago roots by different Phytophthora species. A, Toluidine blue-stained plastic section (6 $\mu$ m) of $P$. capsici-infected Medicago root. Haustoria are marked by black arrowheads. B, Toluidine blue-stained plastic section of $P$. cinnamomi-infected Medicago root. Haustoria are marked by black arrowheads. Chlamydospores $(\mathrm{Ch})$ are forming in plant cells. C, Toluidine blue-stained plastic section (6 $\mu \mathrm{m})$ of P. medicaginis-infected Medicago root. Haustoria are marked by black arrowheads. D, Light microscopy image of a hand section through a $P$. medicaginis infected root. Outlines of hyphae between cells are visible as well as haustoria entering cells (black arrowheads). Scale bars represent $25 \mu \mathrm{m}$. 
root colonization 3 days postinoculation (dpi), using light microscopy on living roots or sections of plastic-embedded roots. All Phytophthora species were able to infect Medicago roots and haustoria were observed in all interactions (Figs. 1 and 2). Medicago roots infected by $P$. capsici showed most severe disease symptoms, as judged by a strong brown coloration of the roots and a high abundance of intracellular hyphae throughout the root, which likely represents necrotrophic colonization (Fig. 1A). Infection by P. cinnamomi, P. medicaginis, and $P$. palmivora was more subtle, as hyphae were predominantly present in the intercellular spaces of the outer cell layers of the root (Figs. 1B and C and 2). We selected P. palmivora for further studies, as transgenic lines expressing green fluorescent protein (GFP) or $\beta$-glucuronidase (GUS) (van West et al. 1999; Vijn and Govers 2003) were available to facilitate imaging of infection events.

\section{Knockout of Medicago genes required for symbiotic} infection does not affect susceptibility toward $P$. palmivora.

To study whether Phytophthora spp. make use of genes required for symbiotic root colonization, we studied the susceptibility of the Medicago mutants listed in Table 1 toward $P$. palmivora. We quantified the spread of infection through Medicago roots after point inoculation, similar to the quantification of lesion length used by Yang and colleagues (2013). Medicago seedlings were inoculated using a mycelial plug of a GUS-expressing P. palmivora transformant. At 4 dpi, GUS staining was used to visualize the spread of hyphae through the roots. We measured the length of the region of the root that was colonized and performed a Mann-Whitney $U$ test to determine the significance of differences between genetic backgrounds. All mutants were in the Jemalong A17 genetic background except for the VAPYRIN mutant (vpy), which is in the R108 genetic background (Table 1). No significant differences were observed between any of the mutants and their respective wild- type control (Fig. 3; Supplementary Table S2). Notably, the spread of hyphae in the R108 background was significantly more extensive $(P<0.001)$ compared with roots in the A17 background. This indicates that R108 is more susceptible than A17 to $P$. palmivora infection.

\section{$P$. palmivora zoospore inoculation assay.}

Analyses of the infection events after inoculation of wildtype plants using mycelial plugs showed that the zone in which haustoria were distinguishable was relatively small, likely due to the point source inoculation. Furthermore, many infected cells along the root contained intracellular hyphae that traversed the cells, which hampered the identification of haustoria. To facilitate more extensive and synchronized haustorium formation along a broader root region and to obtain a less severe infection, we next inoculated Medicago roots with Phytophthora zoospores in a hydroculture system. One-week-old Medicago seedlings were placed in hydroculture by inserting their hypocotyl in plastic foam floating on demineralized water in polystyrene tubes (Fig. 4). Plants were inoculated by adding $10^{4}$ GFP- or GUS-expressing $P$. palmivora zoospores to the water. First, we analyzed the infection process in the wildtype Medicago backgrounds A17 and R108. At 1 dpi, zoospores had germinated and hyphae had penetrated the epidermis (Fig. 2A). This experimental setup resulted in an equal spread of infection events over the entire root length, with a slight bias toward the root tip (data not shown). P. palmivora generally entered Medicago roots by crossing the cells of the epidermis, although it occasionally also penetrated between epidermal cells. Germ tubes entered atrichoblasts as well as root hairs. The hyphae that entered root hairs did not progress in a specific direction, which mostly resulted in aborted infections. Infected epidermal cells were also often heavily colonized with a high abundance of hyphae within a cell. From this primary site of infection, hyphae predominantly progressed parallel to the root
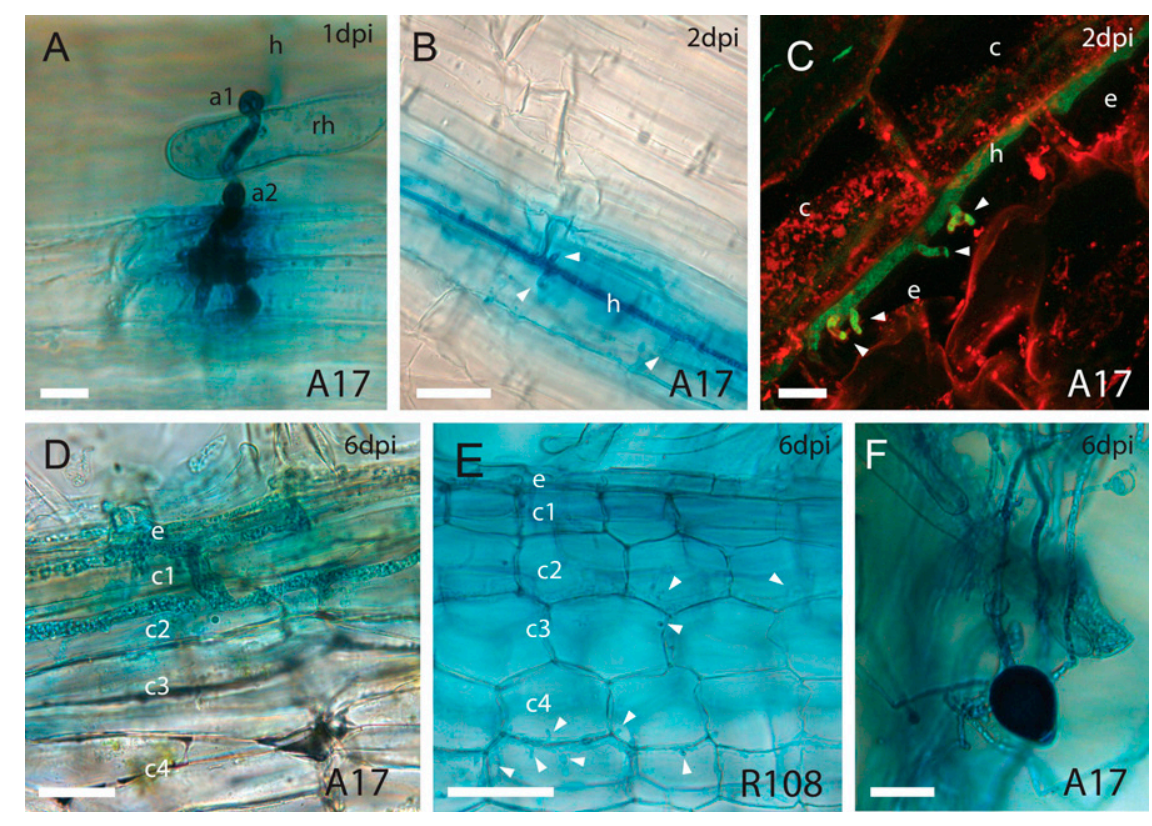

Fig. 2. Infection of Medicago roots by Phytophthora palmivora. A, Z projection of three images showing early infection of a Medicago root by P. palmivora $\beta$-glucuronidase (GUS), $17 \mathrm{~h}$ postinoculation. P. palmivora structures stain dark blue. A hypha (h) arriving at the root forming an initial appressorium (a1) on a root hair (rh), after which it continues growth toward the root. On a root epidermal cell, a second appressorium (a2) is formed, of which hyphae subsequently penetrate the epidermal cells. Scale bar $=25 \mu \mathrm{m}$. B, Hypha (h) growing in the intercellular space in the longitudinal direction of the root, 2 days postinoculation (dpi). Haustoria (white arrowheads) are visible. Scale bar $=25 \mu \mathrm{m}$. C, Projection of confocal image stack, 2 dpi. $P$. palmivora green fluorescent protein infects Medicago, counterstained with FM4-64. A hypha grows in the intercellular space between epidermal cells (e) and cortex cells (c). Haustoria (white arrowheads) are formed in the epidermal cells. FM4-64 staining around the haustoria shows that the haustoria are surrounded by membrane. Scale bar = $10 \mu \mathrm{m}$. D and E, Hand sections through Medicago A17 (D) or R108 (E) roots, 6 dpi with P. palmivora GUS. Epidermis (e) and different cortex layers (c1 to c4) are visible. Haustoria are marked with white arrowheads. Scale bars are $25 \mu \mathrm{m}$. F, Infection 6 dpi, showing a zoosporangium. Scale bar $=25 \mu \mathrm{m}$. 
surface through the intercellular spaces. At 2 dpi, colonization of the root was mainly restricted to the epidermis and outer cortex layer (Fig. 2B and C). Haustoria could be observed in both cell layers. The shape of haustoria varied from digit-like to branched. From 2 dpi onwards, a slight brown coloration of the roots could be observed, which was more pronounced in ecotype R108 compared with A17 (Fig. 4). The brown coloration, which likely represents necrotic cells (Rey et al. 2015; Yang et al. 2013), gradually increased in intensity over the course of infection. At $4 \mathrm{dpi}$, the infection had progressed approximately one cell layer deeper into the root, with hyphae present between the two outermost cortex layers, whereas at $6 \mathrm{dpi}$, some variation in the amount of infected cell layers was present. In the roots of A17, the hyphae remained mainly restricted to the outer cell layers of the root, showing that inward progression of hyphae had halted (Fig. 2D). Further, the shoots showed no macroscopic symptoms (Fig. 4). In contrast, P. palmivora progressed deeper into roots of R108 as compared with A17, with hyphae present between all cortical cell layers and invading the vascular bundle (Fig. 2E). Moreover, the shoots of R108 showed severe macroscopic symptoms; at $4 \mathrm{dpi}$, all shoots of R108 had wilted, compared with one shoot in A17 (Fig. 4) $(n=15)$. On all roots, new zoosporangia were formed, allowing $P$. palmivora to complete its lifecycle (Fig. 2F).

\section{Common symbiotic signaling genes are not required for haustorium formation.}

We used the hydroculture system to study whether any of the symbiotic mutants (Table 1) would be impaired in haustorium formation. To facilitate the visualization of haustoria, we mainly made use of the GUS-expressing P. palmivora strain. At 2, 4, and $6 \mathrm{dpi}$, eight roots were harvested and screened for the presence of haustoria. Haustoria were consistently observed in all mutants, in all roots $(n=24)$ (Fig. 5; Supplementary Fig. S1) over two repetitions of the experiment. Furthermore, at 6 dpi, new zoosporangia were produced on all plant roots, showing that $P$. palmivora is able to complete its lifecycle on all mutants. No obvious differences with respect to root colonization length, intracellular hyphae, and depth of hyphal penetration were observed between the mutants and their corresponding wild-type genetic backgrounds.
Of the ten mutants used in this study, only the ram 2 mutant was previously tested for its ability to accommodate $P$. palmivora. In that study, it was shown that $P$. palmivora is not able to form appressoria on ram2 roots, severely reducing the susceptibility of this mutant plant (Wang et al. 2012). In our hands, zoospore inoculation resulted in colonization of the ram2 mutant and no differences were observed between ram 2 and the wild-type A17. This is in line with the similar susceptibility of ram 2 mutants and wild-type plants to $P$. palmivora after inoculation with mycelial plugs (Fig. 3). We observed normal appressorium formation on the surface of the ram 2 mutant in the hydroculture system. To rule out differences between the strains of $P$. palmivora that were used in our study and that of Wang et al. (2012), we also analyzed the infection of A17 and ram2 with the P. palmivora 16830 strain (Wang et al. 2012). Also, with this strain, appressoria were formed on all ram 2 roots like on wild type, resulting in a successful infection and haustorium formation (Fig. 6) $(n=10)$. On both ram2 and wild-type roots, the length of the germ tube connecting cyst and appressorium was in the same range, indicating that $P$. palmivora had no difficulty in forming appressoria (Fig. 6A and B).

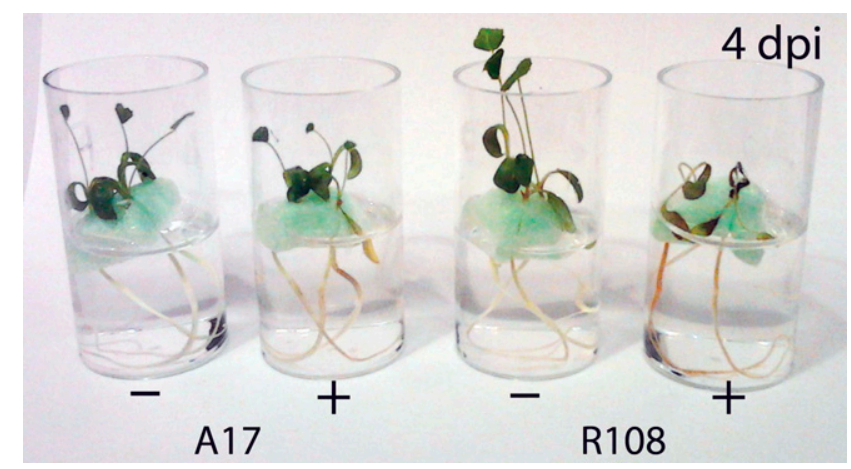

Fig. 4. Experimental setup for zoospore inoculation of Medicago seedlings by Phytophthora palmivora. Seven-day-old Medicago A17 and R108 seedlings are grown in hydroculture tubes $\varnothing=3 \mathrm{~cm}$. P. palmivora inoculated plants $(+)$ and mock inoculated plants $(-)$ are shown at 4 days postinoculation.

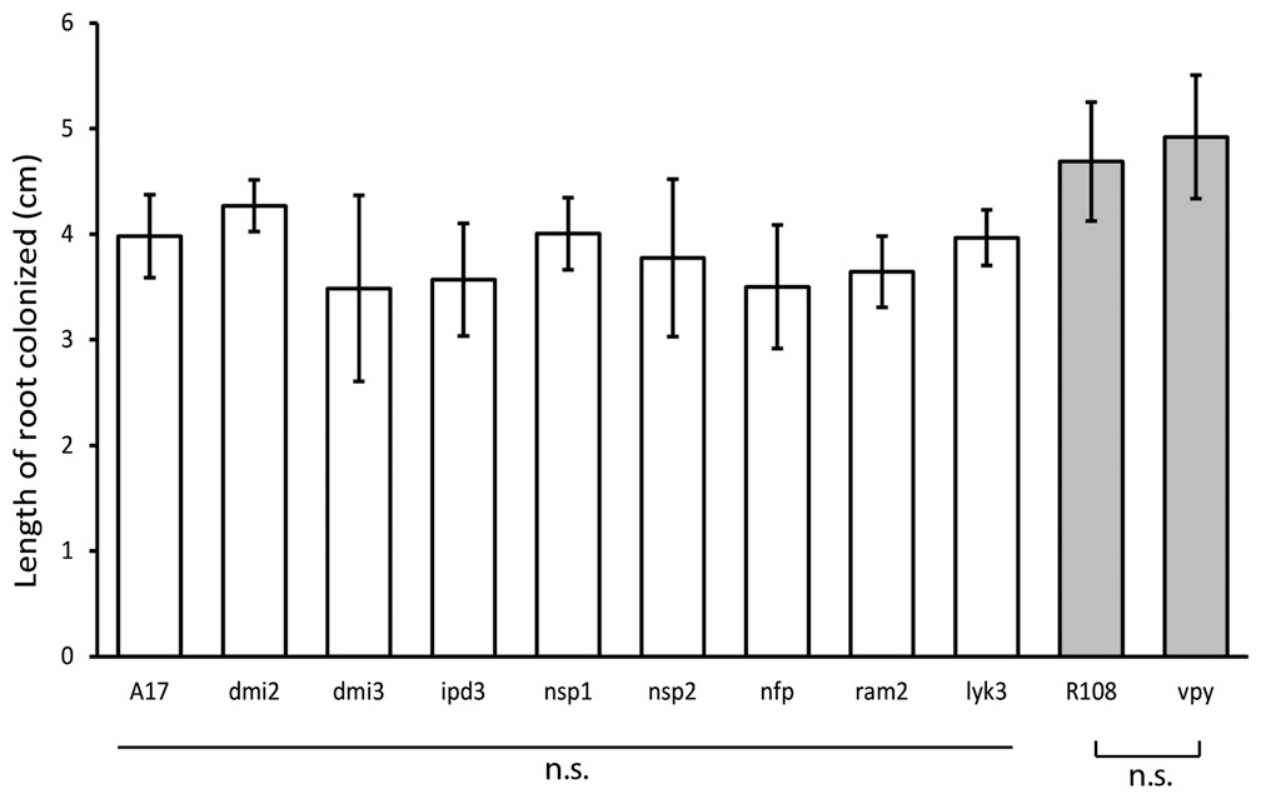

Fig. 3. Mutation of symbiosis genes does not affect susceptibility of Medicago roots toward Phytophthora palmivora. Spread of infection in Medicago mutants after infection with mycelial plugs of $P$. palmivora $\beta$-glucuronidase (GUS) is shown at 4 days postinoculation. The length of the region stained by GUS was measured. N.s. = nonsignificant difference in colonization between mutants and their wild-type background $(n=4, P<0.05)$. 
Together, our observations show that, in Medicago, the Nod factor receptors, the common symbiosis signaling genes, and downstream components are not essential for the formation of a pathogenic host- microbe interface by $P$. palmivora.

\section{Knockdown of the symbiosis-specific v-SNAREs VAMP721d and VAMP721e does not affect haustorium formation.}

Since the link between symbiotic signaling and symbiotic membrane traffic has not been resolved, it is possible that these two mechanisms are independently recruited by microbes. Therefore, although biotrophic pathogens do not require symbiotic signaling genes for haustorium formation, it is still possible that they do require the symbiotic membrane trafficking pathway marked by specific v-SNARE proteins. To determine whether these SNAREs are also required for haustorium formation, we tested the ability of $P$. palmivora to form haustoria in axenic root cultures in which these SNARE genes were silenced. Agrobacterium rhizogenes-transformed roots were generated using the VAMP721d and VAMP721e silencing construct described by Ivanov et al. (2012). Several root cultures were produced and VAMP721d and VAMP721e transcript levels were determined by quantitative reverse transcriptionpolymerase chain reaction (qRT-PCR). Efficient silencing of VAMP721d and VAMP721e was observed, with transcript levels down to 6 and 9\%, respectively, in root culture \#1 (Fig. 7A). This level of silencing completely blocked the ability of the AM fungus Rhizophagus irregularis to form arbuscules. Intraradical hyphae and arbuscule trunks were observed in VAMP721d/e RNAi root cultures, but arbuscule fine-branches did not form, in analogy to the phenotype published by Ivanov et al. (2012). In contrast, empty vector control root cultures did show normal arbuscule formation (Supplementary Fig. S2). Two days after inoculation with $P$. palmivora zoospores, we observed haustoria in both the VAMP721d/e RNAi root cultures (Fig. 7C) as well as in the empty vector root culture (Fig. 7B). This strongly indicates that haustorium formation by $P$. palmivora does not require the symbiotic v-SNAREs.

\section{DISCUSSION}

In this study, we have developed a pathosystem to study the formation of haustoria in the model legume Medicago truncatula. The relatively long biotrophic phase of $P$. palmivora, together with its ability to form haustoria in root cells of Medicago, allowed us to compare the formation of haustoria with symbiotic host-microbe interfaces in the same plant tissue. We made use of the extensive collection of Medicago mutants to study the role of core symbiosis genes that are shared between AM symbiosis and rhizobium symbiosis in plant-pathogen interactions. The susceptibility toward $P$. palmivora was not significantly different in any of the tested Medicago symbiotic mutants, showing that these genes are not required for full virulence. We did, however, observe a higher susceptibility of the wild-type ecotype R108 compared with Jemalong A17, in agreement with data from Samac et al. (2011), which showed more severe disease symptoms on R108 compared with A17 in plants infected with the powdery mildew Erysiphe pisi and Phytophthora medicaginis.

The absence of differences in susceptibility to $P$. palmivora is in contrast with several earlier reports that show that mutations in symbiosis genes can alter plant defense or pathogen entry. Most remarkable is the discrepancy between our results and those of Wang et al. (2012) and Rey et al. (2015) in relation to the susceptibility of the ram 2 mutant toward $P$. palmivora. They reported that $P$. palmivora is unable to form appressoria on ram2 roots, which are impaired in cutin biosynthesis, resulting in a severely reduced colonization (Wang et al. 2012). Similarly, colonization by the oomycete Aphanomyces euteiches was reported to be impaired in ram2 roots (Gobbato et al. 2013). However, in our assays, $P$. palmivora formed appressoria on ram 2 mutant roots like it did on wild-type roots. Furthermore, no differences in root colonization or the ability to form haustoria were observed between ram2 and wild-type roots. Similar results were obtained with the $P$. palmivora strain originally used by Wang and colleagues (2012). These differences might be explained by different growth conditions in the various studies, although both plate inoculations as well as inoculation in hydroculture did not show any defect in our hands. This strongly
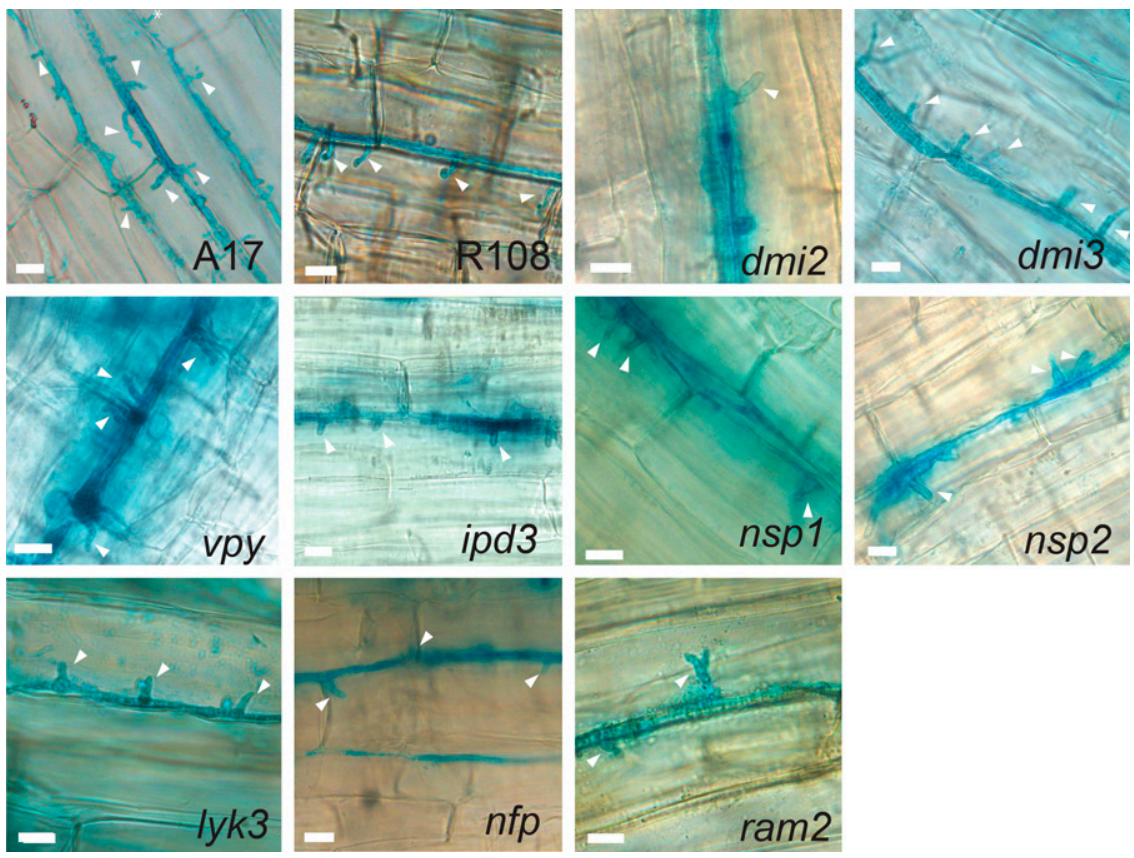

Fig. 5. Haustorium formation in roots of Medicago wild-type plants and symbiosis mutants. Haustoria (white arrowheads) formed in roots of Medicago ecotypes A17 and R108 and different Medicago mutants, 2 days postinoculation. Scale bars represent $10 \mu \mathrm{m}, n=24$. 
suggests that the involvement of cutin as a cue for appressorium formation is not as strict as previously claimed.

The Medicago Nod factor receptor $n f p$ mutant was previously reported to have an increased susceptibility toward the oomycete $A$. euteiches and the fungus $C$. trifolii (Rey et al. 2013). The increased susceptibility of the $n f p$ mutant to A. euteiches and C. trifolii suggests that chitosaccharides released by these pathogens are detected by NFP (a protein controlling Nod factor perception), which contributes to plant defense (Nars et al. 2013; Rey et al. 2013). In our experiments, infection of the $n f p(C 31 / n f p-1)$ knock-out mutant by $P$. palmivora was unaltered compared with wild type. Also, in the recent study by Rey et al. (2015), $P$. palmivora infection was only marginally affected in the $n f p-1$ mutant. This may suggest that (hemi)biotrophic pathogens differ in the extent to which they elicit defense through NFP. Notably, the observed difference correlates with the presence of
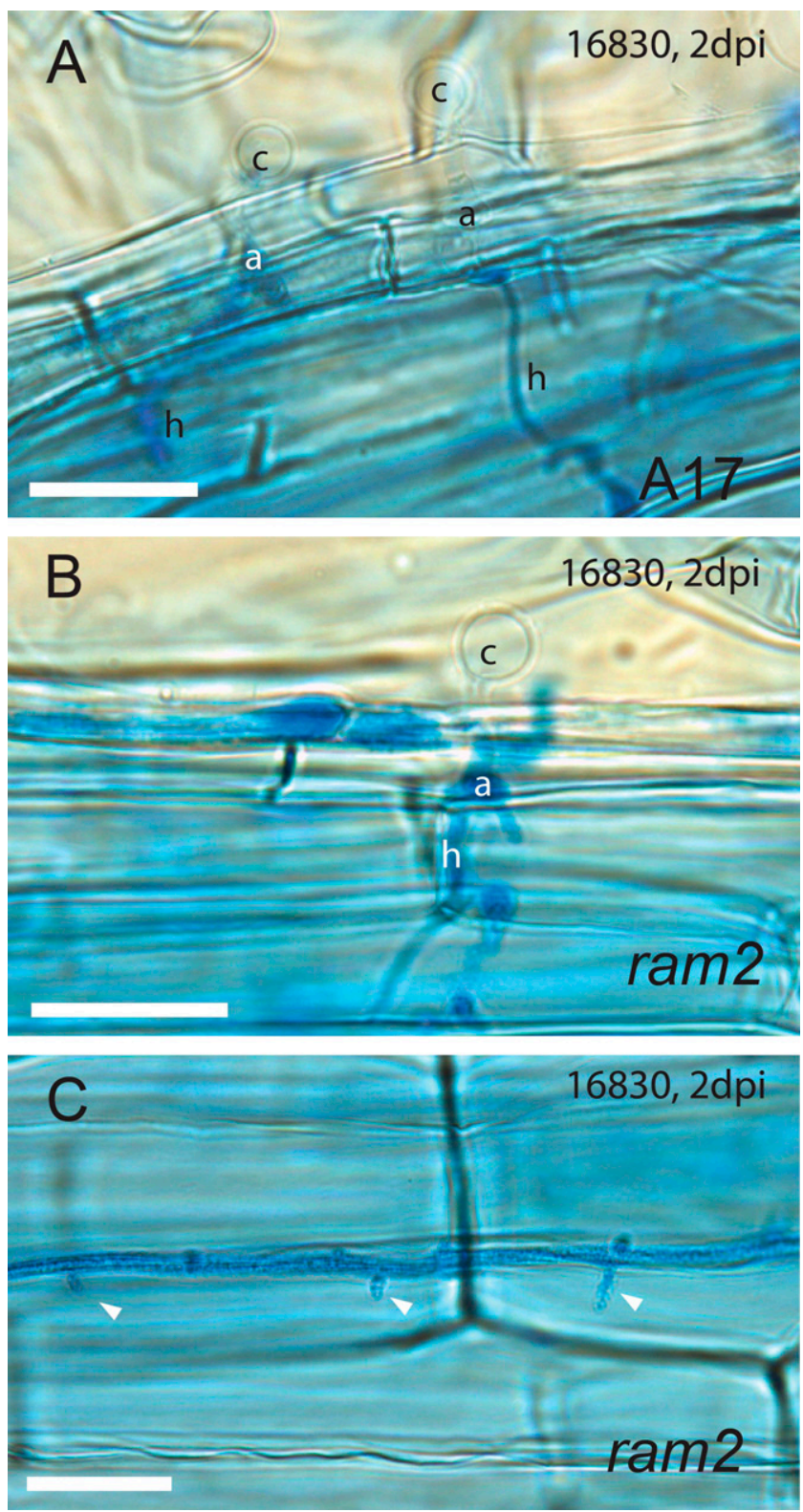

Fig. 6. Medicago ram 2 mutant plants are infected by Phytophthora palmivora similar to wild-type plants. A, Trypan blue-stained roots showing the infection of A17 and $\mathbf{B}$ and $\mathbf{C}, \operatorname{ram} 2$ mutants at 2 days postinoculation with $P$. palmivora isolate 16830 . Germinating cysts (c) with short germtubes form an appressorium (a) from which hyphae (h) penetrate the root. C, In the roots, haustoria (white arrowheads) are formed. Scale bars are $25 \mu \mathrm{m}$. chitosaccharides in the cell walls of $C$. trifolii and A. euteiches and the presumed absence of chitosaccharides in Phytophthora species (Badreddine et al. 2008; Meijer et al. 2006; Nars et al. 2013).

Our results show that, in the roots, the common SYM genes are not required for haustorium formation or intracellular infection. Thus, in contrast to rhizobia, P. palmivora does not make use of the ancient AM symbiosis program to be hosted inside plant cells. The latter is also in line with the ability of the rice blast fungus Magnaporthe oryzae to intracellulary colonize rice roots mutated in the common SYM gene CCAMK/DMI3 (Marcel et al. 2010). Furthermore, $P$. parasitica has been shown to form haustoria in the roots and leaves of Arabidopsis thaliana, which does not engage in AM symbiosis and, consequently, has lost most genes required for AM symbiosis during evolution (Delaux et al. 2013b; Wang et al. 2011). Similar observations are made in leaves of Lotus japonicus, in which mutations in common SYM genes do not affect haustorium formation by rust fungus Uromyces loti (Mellersh and Parniske
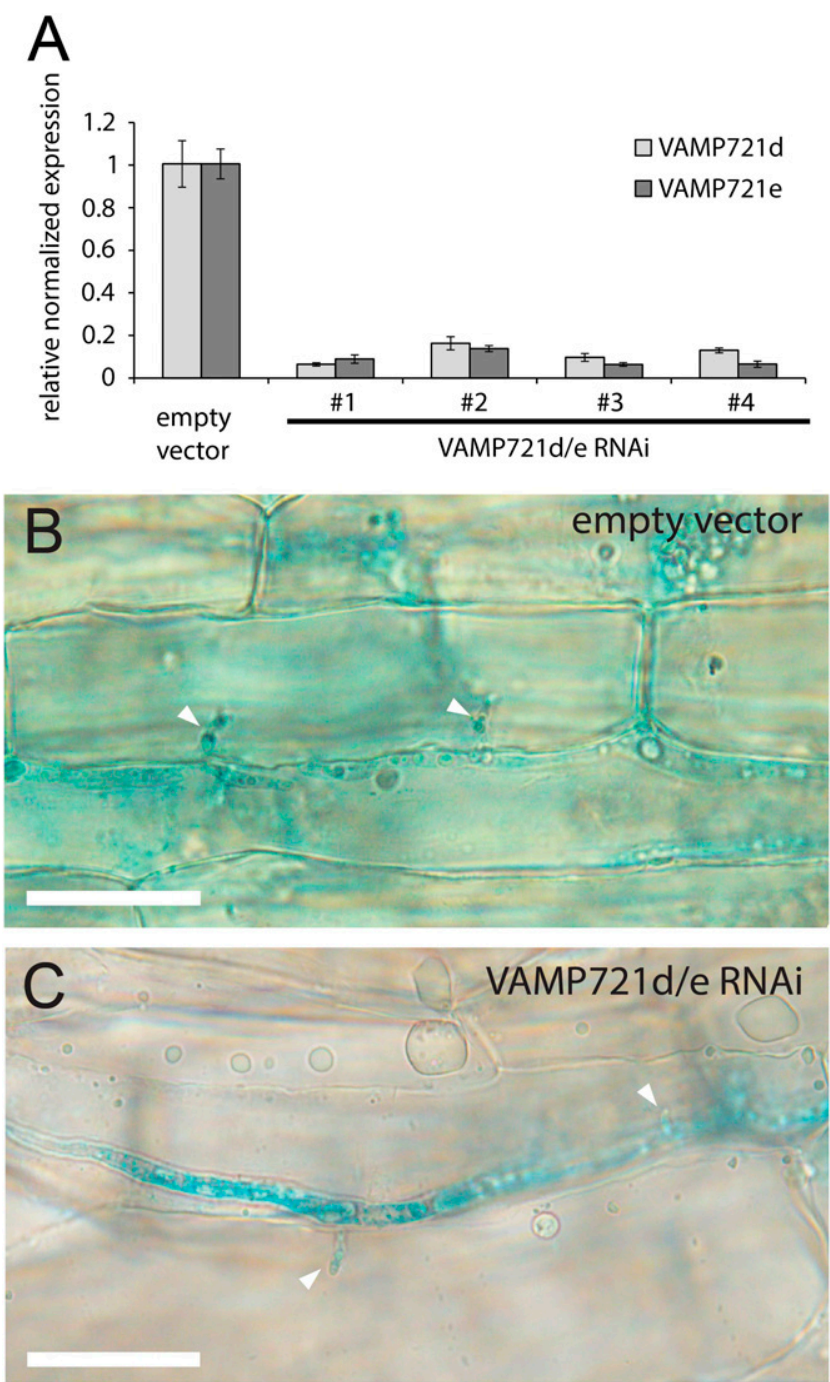

Fig. 7. Haustorium formation in VAMP721d and VAMP721e silenced root cultures. A, Expression levels of VAMP721d and VAMP721e in different VAMP721d- and VAMP721e-silenced root cultures relative to the empty vector control. Expression levels were normalized using MtActin2 and MtUbiquitin10 as reference genes. B and C, Microscopy images of hand sections of a Phytophthora palmivora $\beta$-glucuronidase-infected root cultures, 2 days postinoculation. Haustoria (white arrowheads) were visible in root cultures transformed with an empty vector (B) as well as in VAMP721d- and VAMP721e-silenced cultures (C). Scale bars represent $25 \mu \mathrm{m}$. 
2006). However, it is unclear whether the common SYM genes are active in leaves.

In addition to the involvement of the symbiotic signaling genes, regulation of vesicle trafficking to form a host-microbe interface also appears to be different between $P$. palmivora and symbionts. In the case of arbuscules (or symbiosomes), the formation of the interface requires a specific exocytosis pathway marked by the vesicle SNAREs VAMP721d and VAMP721e (Ivanov et al. 2012). Although we did not completely knock out VAMP721d and VAMP721e and cannot rule out the contribution of the residual transcript levels to haustorium formation, knockdown of both genes to levels that impair arbuscule formation did not affect the ability of $P$. palmivora to form haustoria. Like arbuscules and symbiosomes, haustoria do have a specialized plant-derived interface membrane (the extrahaustorial membrane) that is distinguishable from the plasma membrane ( $\mathrm{Lu}$ et al. 2012). If the formation of the extrahaustorial membrane, indeed, depends on a specialized membrane trafficking pathway directed toward the haustorium, it could rely on other vesicle SNAREs than those required for symbiotic vesicle traffic. The involvement of different membrane trafficking pathways to accommodate symbionts or pathogens may reflect a different requirement to deliver cell-wall degrading or loosening enzymes by the plant, to allow the entry of the microbes. The most significant cell-wall remodeling occurs at the switch from arbuscule trunk (which is still cell-wall bound) to the fine branches that form the actual symbiotic interface, which are devoid of a structured cell wall (Balestrini and Bonfante 2014). AM fungi do not have enzymes to degrade plant cell walls and, like rhizobium bacteria, rely heavily on the host plant to degrade the cell wall to allow the formation of a symbiotic interface (Tisserant et al. 2013). Pathogenic microbes, on the other hand, often do have the capacity to break down the cell wall and might, therefore, be less dependent on the host plant.

In conclusion, we show that $P$. palmivora does not hijack the ancient intracellular accommodation program used by symbiotic microbes to form a biotrophic host-microbe interface. Since symbiotic signaling and defense signaling are partially overlapping (Liang et al. 2014), it is likely that the susceptibility of symbiotic signaling mutants to various pathogens will show species-specific differences. However, we have shown that the presence of the symbiotic intracellular accommodation program is not a general prerequisite for the intracellular infection and haustorium formation by pathogens.

\section{MATERIALS AND METHODS}

\section{Plant growth conditions.}

Except for ram 2 mutant seeds, Medicago truncatula seeds were scarified in $96 \% \mathrm{H}_{2} \mathrm{SO}_{4}$ for $10 \mathrm{~min}$; ram 2 seeds were scarified with sandpaper. All seeds were washed in demi-water and were subsequently surface-sterilized in $4 \% \mathrm{NaClO}$. After sterilization, the seeds were washed in sterile demi-water, were incubated for 1 day at $4{ }^{\circ} \mathrm{C}$, and were pregerminated on Farhaeus plates (Limpens et al. 2004) for 1 day at room temperature in the dark. Seedlings were transferred to Farhaeus plates and were grown for 7 days at $25^{\circ} \mathrm{C}$ at a 16-h light and 8-h dark regime until inoculation. The Medicago mutants used in this study are listed in Table 1 . The mutations in all mutant lines were verified by sequence analysis.

\section{Medicago transformation.}

Medicago A17 plants were transformed using Agrobacterium rhizogenes MSU440, carrying RNA silencing constructs targeting MtVAMP721d and MtVAMP721e, according to Ivanov et al. (2012). Transformed roots were transferred to solid M medium (Bécard and Fortin 1988) containing $300 \mu \mathrm{g}$ of Cefotaxime per milliliter and were incubated at $25^{\circ} \mathrm{C}$ in the dark, until a growing root culture was obtained. The level of VAMP721d and VAMP721e silencing was determined by qRTPCR, after which the root culture with the lowest VAMP721d and VAMP72le transcript levels was selected and maintained on solid M medium until inoculation.

\section{RNA isolation and qRT-PCR.}

RNA was isolated from root cultures with a plant RNA mini kit (EZNA), according to manufacturer's instructions. For cDNA synthesis using the iScript cDNA synthesis kit (Bio-Rad), $1 \mu \mathrm{g}$ of RNA was used, according to manufacturer's instructions. Equal amounts of cDNA were used for qPCR using SYBR green supermix (Bio-Rad) in a Bio-Rad CFX connect real-time system qPCR machine. Gene expression levels were determined using gene-specific primers listed in Supplementary Table S1 and cDNA levels were normalized using Actin2 and Ubiquitin10 as reference genes, using the $\Delta \Delta \mathrm{Ct}$ method (Livak and Schmittgen 2001).

\section{Phytophthora strains and culture conditions.}

We made use of $P$. palmivora isolate 6370 carrying a GUS gene regulated by the constitutive Bremia lactucae pHam34 promoter (Vijn and Govers 2003), P. palmivora 6370 carrying GFP (van West et al. 1999), P. palmivora isolate 16830 (Wang et al. 2012), P. capsici LT3241 (Wang et al. 2013), P. cinnamomi Pe-90 (Serrano et al. 2012), and P. medicaginis CBS119902 and CBS117685 (obtained from the Center for Biological Sequence Analysis Fungal Biodiversity Center culture collection) All Phytophthora species were maintained at $25^{\circ} \mathrm{C}$ on V8 agar plates (20\% V8 vegetable juice [Campbell's] $3.5 \mathrm{~g}$ of $\mathrm{CaCO}_{3}$ per liter, $15 \mathrm{~g}$ of micro agar per liter (Duchefa). V8 medium for culturing transgenic lines was supplemented with (per milliliter) $100 \mu \mathrm{g}$ of ampicillin, $10 \mu \mathrm{g}$ of amphotericin B, $20 \mu \mathrm{g}$ of vancomycin, and $20 \mu \mathrm{g}$ of geneticin.

\section{P. palmivora zoospore production.}

For zoospore production, 4-day-old plates fully grown with $P$. palmivora were submerged in $10 \mathrm{ml}$ of $4^{\circ} \mathrm{C}$ demi-water and were incubated at $25^{\circ} \mathrm{C}$ for $30 \mathrm{~min}$ to release the zoospores. Successful release of zoospores was confirmed by microscopy. The zoospore suspension was filtered through a $50-\mu \mathrm{m}$ nylon mesh. The suspension was centrifuged for $5 \mathrm{~min}$ at $100 \times g$ to concentrate zoospores. After centrifugation, the zoospores were resuspended in demi-water to a concentration of $1 \times 10^{5}$ zoospores per milliliter.

\section{Plant inoculation.}

For inoculation of Medicago with mycelial plugs, 1-weekold Medicago plants growing on Farhaeus plates were used. Mycelial plugs $(\varnothing \approx 3 \mathrm{~mm})$ were punched from V8 plates on which Phytophthora spp. were cultured for 4 days. Plugs were placed on Medicago roots, with the mycelium side contacting the root. Inoculated plants were incubated at $25^{\circ} \mathrm{C}$ at a $16-\mathrm{h}$ light and 8-h dark regime until analysis.

Before inoculation with zoospores, seedlings or root cultures were transferred to tubes containing $20 \mathrm{ml}$ of demi-water. Root cultures were washed three times for $1 \mathrm{~h}$ in demi-water to remove residual sugar-containing $\mathrm{M}$ medium from their surface. The hypocotyls of seedlings were inserted into a plastic foam floater to prevent the cotyledons from submersion. For inoculation, $100 \mu \mathrm{l}$ of zoospore suspension was added. Inoculated plants were incubated at $25^{\circ} \mathrm{C}$ under a 16 -h light and 6-h dark regime until analysis. Eight tubes containing three seedlings each were used per mutant. Seedlings from each tube were examined at 2, 4, and 6 dpi. 


\section{Mycorrizal inocculation.}

An axenic Rhizophagus irregularis culture was maintained on a Medicago root culture growing on solid $\mathrm{M}$ medium (Bécard and Fortin 1988). The VAMP721d- and VAMP72le-silenced root cultures and the empty vector control root cultures, growing on solid $\mathrm{M}$ medium, were inoculated by transferring hyphae and spores from the donor plate to the root culture plates. After 4 weeks, the infection was analyzed.

\section{Trypan blue staining.}

Roots were placed in trypan blue staining solution $(60 \%$ ethanol, $10 \%$ phenol, $10 \%$ glycerol, $10 \%$ lactic acid, $10 \%$ water, and $0.02 \%$ trypan blue) and were heated to $60^{\circ} \mathrm{C}$ for $2 \mathrm{~h}$. After staining, the roots were destained for $16 \mathrm{~h}$ in chloral hydrate solution $(2.5 \mathrm{~g} / \mathrm{ml})$, replacing the destaining solution twice. After destaining, the roots were mounted in glycerol on microscope slides for imaging.

\section{WGA staining.}

Roots were cleared in $10 \% \mathrm{KOH}$ at $60^{\circ} \mathrm{C}$ for $2 \mathrm{~h}$. Then, the roots were washed three times in PBS $(150 \mathrm{mM} \mathrm{NaCl}, 10 \mathrm{mM}$ $\mathrm{Na}_{2} \mathrm{HPO}_{4}, 1.8 \mathrm{mM} \mathrm{KH}_{2} \mathrm{PO}_{4}, \mathrm{pH}$ 7.4), after which the roots were stained in $0.2 \mu \mathrm{g}$ of WGA-Alexafluor 488 per milliliter (Molecular Probes) in PBS at room temperature for $16 \mathrm{~h}$.

\section{Plastic embedding.}

Before plastic embedding, roots were fixed by vacuum infiltrating $5 \%$ glutarealdehyde in $0.1 \mathrm{M} \mathrm{PO}_{4}$ buffer (pH 7). After fixation, the roots were dehydrated in an ethanol dehydration series (30,50, and 70\%, $1 \mathrm{~h}$ each, followed by $100 \%$ ethanol for $16 \mathrm{~h}$ ) and were embedded in Technovit 7100 (Heraeus-Kulzer). Sections of $6 \mu \mathrm{m}$ were cut using a microtome and were transferred to microscope slides. Sections were stained in $0.05 \mathrm{M}$ toluidine blue for $30 \mathrm{~s}$ and were destained in water for $10 \mathrm{~min}$.

\section{GUS staining.}

Roots were harvested by cutting of the roots at the junction with the hypocotyl. Roots or root cultures inoculated with P. palmivora GUS were washed three times in $0.1 \mathrm{M} \mathrm{PO}_{4}$ buffer ( $\mathrm{pH}$ 7). After washing, roots were submerged in GUS buffer (3\% glucose, $5 \mathrm{mM}$ EDTA, $0.5 \mathrm{mM}$ ferrocyanide, $0.5 \mathrm{mM}$ ferricyanide, $0.5 \mathrm{~g}$ of X-gluc per liter in $0.1 \mathrm{M} \mathrm{PO}_{4}$ buffer $(\mathrm{pH} 7)$ ) and were vacuum infiltrated for $30 \mathrm{~min}$. The roots were incubated at $37^{\circ} \mathrm{C}$ for approximately $1 \mathrm{~h}$, until a clear blue staining could be observed. The samples were cleared in $30 \%$ ethanol.

\section{Quantification of infection.}

After GUS staining, the roots were imaged using a flatbed scanner. The length of blue staining in the entire root was measured using the measurement tool in ImageJ software. The significance of differences was determined using a MannWhitney $U$ test in the IBM SPSS 22 software.

\section{Microscopy.}

Roots stained with trypan blue, GUS, or embedded in plastic were examined with a Leica DM5500 light microscope. Infection by $P$. palmivora GFP was analyzed with a Zeiss LSM550 inverted confocal microscope. A 488-nm laser was used for excitation of GFP, propidium iodide, and FM4-64. GFP emission was observed between 505 and $530 \mathrm{~nm}$, whereas propidium iodide and FM4-64 emission was observed between 560 and $650 \mathrm{~nm}$.

\section{ACKNOWLEDGMENTS}

We thank S. Kamoun for providing $P$. palmivora isolate 16830 , and G. Oldroyd and J. Murray for the Medicago mutant lines ram 2 and vapyrin, respectively. R. Huisman, T. Bisseling, and E. Limpens are supported by the
European Research Council (ERC-2011-AdG294790). K. Bouwmeester is supported by a STW-VENI grant from The Netherlands Organization for Scientific Research.

\section{LITERATURE CITED}

Badreddine, I., Lafitte, C., Heux, L., Skandalis, N., Spanou, Z., Martinez, Y., Esquerré-Tugayé, M. T., Bulone, V., Dumas, B., and Bottin, A. 2008. Cell wall chitosaccharides are essential components and exposed patterns of the phytopathogenic oomycete Aphanomyces euteiches. Eukaryot. Cell 7: 1980-1993.

Bainard, L. D., Bainard, J. D., Newmaster, S. G., and Klironomos, J. N. 2011. Mycorrhizal symbiosis stimulates endoreduplication in angiosperms. Plant Cell Environ. 34:1577-1585.

Balestrini, R., and Bonfante, P. 2014. Cell wall remodeling in mycorrhizal symbiosis: A way towards biotrophism. Front. Plant Sci. 5:237.

Baxter, L., Tripathy, S., Ishaque, N., Boot, N., Cabral, A., Kemen, E., Thines, M., Ah-Fong, A., Anderson, R., Badejoko, W., Bittner-Eddy, P., Boore, J. L., Chibucos, M. C., Coates, M., Dehal, P., Delehaunty, K., Dong, S., Downton, P., Dumas, B., Fabro, G., Fronick, C., Fuerstenberg, S. I., Fulton, L., Gaulin, E., Govers, F., Hughes, L., Humphray, S., Jiang, R. H. Y., Judelson, H., Kamoun, S., Kyung, K., Meijer, H., Minx, P., Morris, P., Nelson, J., Phuntumart, V., Qutob, D., Rehmany, A., RougonCardoso, A., Ryden, P., Torto-Alalibo, T., Studholme, D., Wang, Y., Win, J., Wood, J., Clifton, S. W., Rogers, J., Van den Ackerveken, G., Jones, J. D. G., McDowell, J. M., Beynon, J., and Tyler, B. M. 2010. Signatures of adaptation to obligate biotrophy in the Hyaloperonospora arabidopsidis genome. Science 330:1549-1551.

Bécard, G., and Fortin, J. A. 1988. Early events of vesicular arbuscular mycorrhiza formation on Ri T-DNA transformed roots. New Phytol. 108: 211-218.

Ben Amor,B., Shaw, S. L., Oldroyd, G. E. D., Maillet, F., Penmetsa, R. V., Cook, D., Long, S. R., Dénarié, J., and Gough, C. 2003. The NFP locus of Medicago truncatula controls an early step of Nod factor signal transduction upstream of a rapid calcium flux and root hair deformation. Plant J. 34:495-506.

Chandran, D., Inada, N., Hather, G., Kleindt, C. K., and Wildermuth, M. C. 2010. Laser microdissection of Arabidopsis cells at the powdery mildew infection site reveals site-specific processes and regulators. Proc. Natl. Acad. Sci. U.S.A. 107:460-465.

De Mita, S., Streng, A., Bisseling, T., and Geurts, R. 2014. Evolution of a symbiotic receptor through gene duplications in the legume-rhizobium mutualism. New Phytol. 201:961-972.

Delaux, P. M., Bécard, G., and Combier, J. P. 2013a. NSP1 is a component of the Myc signaling pathway. New Phytol. 199:59-65.

Delaux, P.M., Séjalon-Delmas, N., Bécard, G., and Ané, J.M. 2013b. Evolution of the plant-microbe symbiotic 'toolkit' Trends Plant Sci. 18: 298-304.

Doyle, J. J. 2011. Phylogenetic perspectives on the origins of nodulation. Mol. Plant-Microbe Interact. 24:1289-1295.

Endre, G., Kereszt, A., Kevei, Z., Mihacea, S., Kaló, P., and Kiss, G. B. 2002. A receptor kinase gene regulating symbiotic nodule development. Nature 417:962-966.

Genre, A., Chabaud, M., Balzergue, C., Puech-Pagès, V., Novero, M., Rey, T., Fournier, J., Rochange, S., Bécard, G., Bonfante, P., and Barker, D.G. 2013. Short-chain chitin oligomers from arbuscular mycorrhizal fungi trigger nuclear $\mathrm{Ca} 2+$ spiking in Medicago truncatula roots and their production is enhanced by strigolactone. New Phytol. 198:190-202.

Genre, A., Ortu, G., Bertoldo, C., Martino, E., and Bonfante, P. 2009. Biotic and abiotic stimulation of root epidermal cells reveals common and specific responses to arbuscular mycorrhizal fungi. Plant Physiol. 149: 1424-1434.

Gherbi, H., Markmann, K., Svistoonoff, S., Estevan, J., Autran, D., Giczey, G., Auguy, F., Péret, B., Laplaze, L., Franche, C., Parniske, M., and Bogusz, D. 2008. SymRK defines a common genetic basis for plant root endosymbioses with arbuscular mycorrhiza fungi, rhizobia, and Frankiabacteria. Proc. Natl. Acad. Sci. U.S.A. 105:4928-4932.

Gobbato, E., Wang, E., Higgins, G., Bano, S. A., Henry, C., Schultze, M., and Oldroyd, G. E. D. 2013. RAM1 and RAM2 function and expression during arbuscular mycorrhizal symbiosis and Aphanomyces euteiches colonization. Plant Signal. Behav. 8:10.

Güimil, S., Chang, H.S., Zhu, T., Sesma, A., Osbourn, A., Roux, C., Ioannidis, V., Oakeley, E.J., Docquier, M., Descombes, P., Briggs, S.P., and Paszkowski, U. 2005. Comparative transcriptomics of rice reveals an ancient pattern of response to microbial colonization. Proc. Natl. Acad. Sci. U.S.A. 102:8066-8070. 
Gutjahr, C., and Parniske, M. (2013). Cell and developmental biology of arbuscular mycorrhiza symbiosis. Annu. Rev. Cell. Dev. Bi. 29:593-617.

Hardham, A. R. 2007. Cell biology of plant-oomycete interactions. Cell. Microbiol. 9:31-39.

Harrison, M. J. 2012. Cellular programs for arbuscular mycorrhizal symbiosis. Curr. Opin. Plant Biol. 15:691-698.

Horváth, B., Yeun, L. H., Domonkos, A., Halász, G., Gobbato, E., Ayaydin, F., Miró, K., Hirsch, S., Sun, J., Tadege, M., Ratet, P., Mysore, K. S., Ané, J. M., Oldroyd, G. E. D., and Kaló, P. 2011. Medicago truncatula IPD3 is a member of the common symbiotic signaling pathway required for rhizobial and mycorrhizal symbioses. Mol. Plant-Microbe Interact. 24: 1345-1358.

Huisman, R., Ovchinnikova, E., Bisseling, T., and Limpens, E. 2012. Endocytic accommodation of microbes in plants. Pages 271-295 in: Endocytosis in Plants. J. Samaj, ed. Springer-Verlag Berlin.

Ivanov, S., Fedorova, E. E., Limpens, E., De Mita, S., Genre, A., Bonfante, P., and Bisseling, T. 2012. Rhizobium-legume symbiosis shares an exocytotic pathway required for arbuscule formation. Proc. Natl. Acad Sci. U.S.A. 109:8316-8321.

Kaló, P., Gleason, C., Edwards, A., Marsh, J., Mitra, R. M., Hirsch, S., Jakab, J., Sims, S., Long, S. R., Rogers, J., Kiss, G. B., Downie, J. A., and Oldroyd, G. E. D. 2005. Nodulation signaling in legumes requires NSP2, a member of the GRAS family of transcriptional regulators. Science 308: 1786-1789.

Lévy, J., Bres, C., Geurts, R., Chalhoub, B., Kulikova, O., Duc, G., Journet, E. P., Ané, J. M., Lauber, E., Bisseling, T., Dénarié, J., Rosenberg, C., and Debellé, F. 2004. A putative $\mathrm{Ca}^{+}$and calmodulin-dependent protein kinase required for bacterial and fungal symbioses. Science 303: 1361-1364.

Liang, Y., Tóth, K., Cao, Y., Tanaka, K., Espinoza, C., and Stacey, G. 2014. Lipochitooligosaccharide recognition: An ancient story. New Phytol. 204:289-296.

Limpens, E., Franken, C., Smit, P., Willemse, J., Bisseling, T., and Geurts, R. 2003. LysM domain receptor kinases regulating rhizobial Nod factorinduced infection. Science 302:630-633.

Limpens, E., Ramos, J., Franken, C., Raz, V., Compaan, B., Franssen, H., Bisseling, T., and Geurts, R. 2004. RNA interference in Agrobacterium rhizogenes-transformed roots of Arabidopsis and Medicago truncatula. J. Exp. Bot. 55:983-992.

Livak, K. J., and Schmittgen, T. D. 2001. Analysis of relative gene expression data using real-time quantitative PCR and the $2^{-\Delta \Delta C T}$ method. Methods 25:402-408.

Lu, Y. J., Schornack, S., Spallek, T., Geldner, N., Chory, J., Schellmann, S., Schumacher, K., Kamoun, S., and Robatzek, S. 2012. Patterns of plant subcellular responses to successful oomycete infections reveal differences in host cell reprogramming and endocytic trafficking. Cell. Microbiol. 14:682-697.

Maillet, F., Poinsot, V., André, O., Puech-Pagès, V., Haouy, A., Gueunier, M., Cromer, L., Giraudet, D., Formey, D., Niebel, A., Martinez, E. A., Driguez, H., Bécard, G., and Dénarié, J. 2011. Fungal lipochitooligosaccharide symbiotic signals in arbuscular mycorrhiza. Nature 469 : 58-63.

Marcel, S., Paszkowski, U., Sawers, R., Oakeley, E., and Angliker, H. 2010. Tissue-adapted invasion strategies of the rice blast fungus Magnaporthe oryzae. Plant Cell 22:3177-3187.

Meijer, H.J.G., Van De Vondervoort, P.J.I., Qing, Y.Y., De Koster, C.G., Klis, F.M., Govers, F., and De Groot, P.W.J. 2006. Identification of cell wall-associated proteins from Phytophthora ramorum. Mol- PlantMicrobe Interact. 19:1348-1358.

Mellersh, D., and Parniske, M. 2006. Common symbiosis genes of Lotus japonicus are not required for intracellular accommodation of the rust fungus Uromyces loti. New Phytol. 170:641-644.

Murray, J. D., Muni, R. R. D., Torres-Jerez, I., Tang, Y., Allen, S., Andriankaja, M., Li, G., Laxmi, A., Cheng, X., Wen, J., Vaughan, D., Schultze, M., Sun, J., Charpentier, M., Oldroyd, G., Tadege, M., Ratet, P., Mysore, K. S., Chen, R., and Udvardi, M. K. 2011. Vapyrin, a gene essential for intracellular progression of arbuscular mycorrhizal symbiosis, is also essential for infection by rhizobia in the nodule symbiosis of Medicago truncatula. Plant J. 65:244-252.

Nakagawa, T., Kaku, H., Shimoda, Y., Sugiyama, A., Shimamura, M., Takanashi, K., Yazaki, K., Aoki, T., Shibuya, N., and Kouchi, H. 2011. From defense to symbiosis: Limited alterations in the kinase domain of LysM receptor-like kinases are crucial for evolution of legumeRhizobium symbiosis. Plant J. 65:169-180.

Nars, A., Lafitte, C., Chabaud, M., Drouillard, S., Mélida, H., Danoun, S., Le Costaouëc, T., Rey, T., Benedetti, J., Bulone, V., Barker, D. G., Bono, J. J., Dumas, B., Jacquet, C., Heux, L., Fliegmann, J., and Bottin, A. 2013. Aphanomyces euteiches cell wall fractions containing novel glucan-chitosaccharides induce defense genes and nuclear calcium oscillations in the plant host Medicago truncatula. PLoS One 8:e75039.

O'Connell, R. J., and Panstruga, R. 2006. Tête à tête inside a plant cell: Establishing compatibility between plants and biotrophic fungi and oomycetes. New Phytol. 171:699-718.

Oldroyd, G. E. D. 2013. Speak, friend, and enter: Signalling systems that promote beneficial symbiotic associations in plants. Nat. Rev. Microbiol 11:252-263.

Op den Camp, R., Streng, A., De Mita, S., Cao, Q., Polone, E., Liu, W., Ammiraju, J. S. S., Kudrna, D., Wing, R., Untergasser, A., Bisseling, T., and Geurts, R. 2011. LysM-type mycorrhizal receptor recruited for rhizobium symbiosis in nonlegume Parasponia. Science 331:909-912.

Ovchinnikova, E., Journet, E. P., Chabaud, M., Cosson, V., Ratet, P., Duc, G., Fedorova, E., Liu, W., den Camp, R. O., Zhukov, V., Tikhonovich, I., Borisov, A., Bisseling, T., and Limpens, E. 2011. IPD3 controls the formation of nitrogen-fixing symbiosomes in pea and Medicago spp Mol. Plant-Microbe Interact. 24:1333-1344.

Parniske, M. 2000. Intracellular accommodation of microbes by plants: A common developmental program for symbiosis and disease? Curr. Opin. Plant Biol. 3:320-328.

Pumplin, N., Mondo, S. J., Topp, S., Starker, C. G., Gantt, J. S., and Harrison, M. J. 2010. Medicago truncatula vapyrin is a novel protein required for arbuscular mycorrhizal symbiosis. Plant J. 61:482-494.

Redecker, D., Kodner, R., and Graham, L. E. 2000. Glomalean fungi from the Ordovician. Science 289:1920-1921.

Rey, T., Chatterjee, A., Buttay, M., Toulotte, J., and Schornack, S. 2015. Medicago truncatula symbiosis mutants affected in the interaction with a biotrophic root pathogen. New Phytol. 206:497-500.

Rey, T., Nars, A., Bonhomme, M., Bottin, A., Huguet, S., Balzergue, S., Jardinaud, M. F., Bono, J. J., Cullimore, J., Dumas, B., Gough, C., and Jacquet, C. 2013. NFP, a LysM protein controlling Nod factor perception, also intervenes in Medicago truncatula resistance to pathogens. New Phytol. 198:875-886.

Rey, T., and Schornack, S. 2013. Interactions of beneficial and detrimental root-colonizing filamentous microbes with plant hosts. Genome Biol $14: 121$

Samac, D. A., Peñuela, S., Schnurr, J. A., Hunt, E. N., Foster-Hartnett, D., Vandenbosch, K. A., and Gantt, J. S. 2011. Expression of coordinately regulated defence response genes and analysis of their role in disease resistance in Medicago truncatula. Mol. Plant Pathol. 12:786-798.

Serrano, M.S., Fernández-Rebollo, P., de Vita, P., and Sánchez, M.E. 2012. Susceptibility of common herbaceous crops to Phytophthora cinnamomi and its influence on Quercus root rot in rangelands. Eur. J. Plant Pathol. 134:409-414.

Smit, P., Raedts, J., Portyanko, V., Debellé, F., Gough, C., Bisseling, T., and Geurts, R. 2005. NSP1 of the GRAS protein family is essential for rhizobial Nod factor-induced transcription. Science 308:1789-1791.

Spanu, P. D., Abbott, J. C., Amselem, J., Burgis, T. A., Soanes, D. M., Stüber, K., Ver Loren van Themaat, E., Brown, J. K. M., Butcher, S. A., Gurr, S. J., Lebrun, M. H., Ridout, C. J., Schulze-Lefert, P., Talbot, N. J., Ahmadinejad, N., Ametz, C., Barton, G. R., Benjdia, M., Bidzinski, P., Bindschedler, L. V., Both, M., Brewer, M. T., Cadle-Davidson, L., CadleDavidson, M. M., Collemare, J., Cramer, R., Frenkel, O., Godfrey, D. Harriman, J., Hoede, C., King, B. C., Klages, S., Kleemann, J., Knoll, D., Koti, P. S., Kreplak, J., López-Ruiz, F. J., Lu, X., Maekawa, T., Mahanil, S., Micali, C., Milgroom, M. G., Montana, G., Noir, S., O’Connell, R. J., Oberhaensli, S., Parlange, F., Pedersen, C., Quesneville, H., Reinhardt, R., Rott, M., Sacristán, S., Schmidt, S. M., Schön, M., Skamnioti, P., Sommer, H., Stephens, A., Takahara, H., Thordal-Christensen, H., Vigouroux, M., Wessling, R., Wicker, T., and Panstruga, R. 2010 Genome expansion and gene loss in powdery mildew fungi reveal tradeoffs in extreme parasitism. Science 330:1543-1546.

Svistoonoff, S., Hocher, V., and Gherbi, H. 2014. Actinorhizal root nodule symbioses: What is signalling telling on the origins of nodulation? Curr. Opin. Plant Biol. 20:11-18.

Tisserant, E., Malbreil, M., Kuo, A., Kohler, A., Symeonidi, A., Balestrini, R., Charron, P., Duensing, N., Frei dit Frey, N., Gianinazzi-Pearson, V., Gilbert, L. B., Handa, Y., Herr, J. R., Hijri, M., Koul, R., Kawaguchi, M., Krajinski, F., Lammers, P. J., Masclaux, F. G., Murat, C., Morin, E., Ndikumana, S., Pagni, M., Petitpierre, D., Requena, N., Rosikiewicz, P., Riley, R., Saito, K., San Clemente, H., Shapiro, H., van Tuinen, D., Bécard, G., Bonfante, P., Paszkowski, U., Shachar-Hill, Y. Y., Tuskan, G. A., Young, J. P., Sanders, I. R., Henrissat, B., Rensing, S. A., Grigoriev, I. V., Corradi, N., Roux, C., and Martin, F. 2013. Genome of an arbuscular mycorrhizal fungus provides insight into the oldest plant symbiosis. Proc. Natl. Acad. Sci. U.S.A. 110:20117-20122.

van West, P., Reid, B., Campbell, T. A., Sandrock, R. W., Fry, W. E., Kamoun, S., and Gow, N. A. R. 1999. Green fluorescent protein (GFP) as a reporter 
gene for the plant pathogenic oomycete Phytophthora palmivora. FEMS (Fed. Eur. Microbiol. Soc.) Microbiol. Lett. 178:71-80.

Vijn, I., and Govers, F. 2003. Agrobacterium tumefaciens mediated transformation of the oomycete plant pathogen Phytophthora infestans. Mol. Plant Pathol. 4:459-467.

Vinardell, J. M., Fedorova, E., Cebolla, A., Kevei, Z., Horvath, G., Kelemen, Z., Tarayre, S., Roudier, F., Mergaert, P., Kondorosi, A., and Kondorosi, E. 2003. Endoreduplication mediated by the anaphasepromoting complex activator CCS52A is required for symbiotic cell differentiation in Medicago truncatula nodules. Plant Cell 15: 2093-2105.

Wang, E., Schornack, S., Marsh, J. F., Gobbato, E., Schwessinger, B., Eastmond, P., Schultze, M., Kamoun, S., and Oldroyd, G. E. D. 2012. A common signaling process that promotes mycorrhizal and oomycete colonization of plants. Curr. Biol. 22:2242-2246.

Wang, Y., Bouwmeester, K., van de Mortel, J. E., Shan, W., and Govers, F. 2013. A novel Arabidopsis-oomycete pathosystem: Differential interactions with Phytophthora capsici reveal a role for camalexin, indole glucosinolates and salicylic acid in defence. Plant Cell Environ. 36:1192-1203.

Wang, Y., Meng, Y., Zhang, M., Tong, X., Wang, Q., Sun, Y., Quan, J., Govers, F., and Shan, W. 2011. Infection of Arabidopsis thaliana by Phytophthora parasitica and identification of variation in host specificity. Mol. Plant Pathol. 12:187-201.

Williamson, V. M., and Hussey, R. S. 1996. Nematode pathogenesis and resistance in plants. Plant Cell 8:1735-1745.

Yang, X., Zhao, W., Hua, C., Zheng, X., Jing, M., Li, D., Govers, F., Meijer, H. J. G., and Wang, Y. 2013. Chemotaxis and oospore formation in Phytophthora sojae are controlled by G-protein-coupled receptors with a phosphatidylinositol phosphate kinase domain. Mol. Microbiol. 88: 382-394.

Zhang, X., Dong, W., Sun, J., Feng, F., Deng, Y., He, Z., Oldroyd, G. E. D., and Wang, E. 2015. The receptor kinase CERK1 has dual functions in symbiosis and immunity signalling. Plant J. 81:258-267. 